\section{Response to: 'Effects of colchicine on risk of cardiovascular events among patients with gout: as evidence accrues, is it time for a randomized trial?' by Giannopoulos and Deftereos}

We appreciate the interest of Drs Giannopoulos and Deftereos ${ }^{1}$ in our recent paper; ${ }^{2}$ they have been focused on colchicine's potential effects in cardiovascular disease in the general population. They inquired about the dosage, duration and indication for colchicine in our cohort. The mean dosage was approximately $0.5 \mathrm{mg}$ per day, with some patients using it every other day and some twice daily. The median duration of colchicine users was approximately 1 year, but many did use it for shorter periods. We do not have information on the indications for use in our database but agree that the cardiovascular effects may differ based on its use for acute attacks or chronic prophylaxis. While we agree with Giannopoulos and Deftereos that mounting a randomised controlled clinical trial is difficult, several trials are currently enrolling non-gout patients testing the potential benefits of colchicine for secondary cardiovascular prevention (clinical trial \# NCT02551094 and \# NCT01906749). We believe that similar trials could be considered in patients with gout in whom colchicine is not infrequently part of chronic care.

\section{Daniel H Solomon, ${ }^{1,2}$ Seoyoung C Kim ${ }^{1,2}$}

${ }^{1}$ Division of Rheumatology, Brigham and Women's Hospital, Boston, Massachusetts, USA

${ }^{2}$ Division of Pharmacoepidemiology, Brigham and Women's Hospital, Boston, Massachusetts, USA
Correspondence to Dr Daniel Solomon, Division of Rheumatology, Brigham and Women's Hospital, 75 Francis Street, Boston, MA 02115, USA; dsolomon@partners.org

Funding This work was partially funded by NIH K24 AR055989.

Competing interests DHS receives salary support from unrelated grants to Brigham and Women's Hospital from Lilly, Pfizer, Genentech, and Amgen. DHS and SCK receive research funding from Astra Zeneca on gout that is unrelated to the current paper. SCK receives salary support from unrelated grants to Brigham and Women's Hospital from Lilly, Genentech and Pfizer.

Provenance and peer review Commissioned; internally peer reviewed.

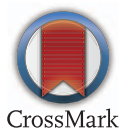

To cite Solomon DH, Kim SC. Ann Rheum Dis 2016;75:e29.

Accepted 10 February 2016

Published Online First 29 February 2016

\section{Linked}

http://dx.doi.org/10.1136/annrheumdis-2016-209294

Ann Rheum Dis 2016;75:e29. doi:10.1136/annrheumdis-2016-209316

\section{REFERENCES}

1 Giannopoulos G, Deftereos S. Effects of colchicine on risk of cardiovascular events among patients with gout: as evidence accrues, is it time for a randomised trial? Ann Rheum Dis 2016;75:e28.

2 Solomon DH, Liu CC, Kuo IH, et al. Effects of colchicine on risk of cardiovascular events and mortality among patients with gout: a cohort study using electronic medical records linked with Medicare claims. Ann Rheum Dis 2015; Published Online First 18 Nov 2015. http://dx.doi.org/10.1136/annrheumdis-2015-207984 